\title{
Macroinvertebrate community responses to a dewatering disturbance gradient in a restored stream
}

\author{
J. D. Muehlbauer ${ }^{1}$, M. W. Doyle ${ }^{1,2}$, and E. S. Bernhardt ${ }^{3}$ \\ ${ }^{1}$ Curriculum for the Environment and Ecology, University of North Carolina, Chapel Hill, NC, USA \\ ${ }^{2}$ Department of Geography, University of North Carolina, Chapel Hill, NC, USA \\ ${ }^{3}$ Biology Department, Duke University, Durham, NC, USA \\ Received: 22 November 2010 - Published in Hydrol. Earth Syst. Sci. Discuss.: 17 December 2010 \\ Revised: 29 May 2011 - Accepted: 30 May 2011 - Published: 9 June 2011
}

\begin{abstract}
Dewatering disturbances are common in aquatic systems and represent a relatively untapped field of disturbance ecology, yet studying dewatering events along gradients in non-dichotomous (i.e. wet/dry) terms is often difficult. Because many stream restorations can essentially be perceived as planned hydrologic manipulations, such systems can make ideal test-cases for understanding processes of hydrological disturbance. In this study we used an experimental drawdown in a 440 ha stream/wetland restoration site to assess aquatic macroinvertebrate community responses to dewatering and subsequent rewetting. The geomorphic nature of the site and the design of the restoration allowed dewatering to occur predictably along a gradient and decoupled the hydrologic response from any geomorphic (i.e. habitat heterogeneity) effects. In the absence of such heterogeneous habitat refugia, reach-scale wetted perimeter and depth conditions exerted a strong control on community structure. The community exhibited an incremental response to dewatering severity over the course of this disturbance, which was made manifest not as a change in community means but as an increase in community variability, or dispersion, at each site. The dewatering also affected inter-species abundance and distributional patterns, as dewatering and rewetting promoted alternate species groups with divergent habitat tolerances. Finally, our results indicate that rapid rewetting - analogous to a hurricane breaking a summer drought - may represent a recovery process rather than an additional disturbance and that such processes, even in newly restored systems, may be rapid.
\end{abstract}

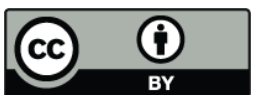

Correspondence to: J. D. Muehlbauer (jeffreym@unc.edu)

\section{Introduction}

Community response to disturbance has long been of central interest to ecologists, and the frequency, type, magnitude, and timing of disturbance can be critical in understanding how communities are able to respond to these events (e.g. Clements, 1936; Connell, 1978). More frequentlydisturbed sites often differ in community composition from less-disturbed areas within the same ecosystem type (Collins, 2000), and disturbance can act as a filter limiting diversity and community composition (Lepori and Malmqvist, 2009). Threshold responses to disturbance are also possible, such that a disturbance of sufficient magnitude may allow communities to transition to a new or alternative stable state (Suding et al., 2004). Many of these community response studies emphasize how disturbance initiates a change in the community mean or centroid, whereby different taxa are present preand post-disturbance. However, another possible response is for communities to simply become more variable with respect to their relative species composition and abundances (i.e. exhibit an increase in community dispersion across sites) over the course of a disturbance, without necessarily affecting the mean of the community ordination (Warwick and Clarke, 1993; Houseman et al., 2008). Yet, to our knowledge, such assessments of dispersion are rare, especially in stream ecosystems.

In streams, Lake (2000) characterized disturbances as falling into 3 classes: (1) rapid, "pulse" disturbances, such as floods; (2) chronic, "press" disturbances, such as persistent toxicant additions; and (3) "ramp" disturbances that increase in severity over time, such as most droughts. Both pulse and ramp-type disturbances are implicitly linked to stream flow and the hydrologic regime, with floods, in particular, having received substantial emphasis from stream ecologists (Resh et al., 1988; Poff et al., 1997). Macroinvertebrates and other

Published by Copernicus Publications on behalf of the European Geosciences Union. 
groups of stream biota often depend on particular hydrologic conditions (Hart and Finelli, 1999), and stream flow characteristics can limit biotic assemblages on both seasonal and interannual timescales (Konrad et al., 2008). Extreme flow alterations can induce regime shifts in communities (Robinson and Uehlinger, 2008) and may reduce diversity and lead to alterations in species dominance (Rader and Belish, 1999). The magnitude of a flow disturbance, rather than just occurrence, is also important (Clausen and Biggs, 2000), possibly with larger invertebrate populations supported under more stable flow conditions (Gislason, 1985). However, due at least in part to the observational nature of most disturbance studies in stream ecology and the differences between flood and flow reduction processes, Bunn and Arthington (2002) have noted that a unified theory for biotic response to flow alteration is still lacking, and have argued for a more theoretical approach.

In comparison to floods, dewaterings (including droughts, agricultural withdrawals, dam diversions, etc.) have been historically understudied in stream ecology (Lake, 2003). This is most likely due to the constraints inherent in designing a sampling strategy to capture fairly unpredictable, drought-type disturbances rather than a lack of interest in these phenomena. In general, studies that have focused on biotic responses to dewatering disturbances have shown recovery to be rapid (Boulton, 2003), but these have strongly emphasized the importance of habitat heterogeneity in providing refugia that allow a subset of organisms to persist in severely dry conditions (Dewson et al., 2007a; Bond et al., 2008; James et al., 2008). However, one study showed that there was often no change in invertebrate densities after droughts (Suren and Jowett, 2006), and another found that invertebrate density actually increased during water abstraction because drying forced invertebrates to congregate in a smaller area, although species richness and evenness did decrease (Dewson et al., 2007b). Most of these studies also cast dewatering disturbances in dichotomous terms (e.g. the stream is experiencing drought or it is not). In the few studies where aquatic community responses along a gradient of dewatering severity have been described, changes in community abundance, density, richness, etc. have been proportional to the magnitude of flow reduction (Miller et al., 2007), although decreases in abundance may only be observed in the least tolerant taxa (James and Suren, 2009).

In the face of climate change and human development increasing the incidence of such extreme hydrologic events (i.e. floods and droughts) as well as habitat loss and fragmentation (including stream channelization and burial), and water quality concerns (eutrophication, sediment and chemical pollution) worldwide, stream and river restoration has become common practice in aquatic ecosystems (Bernhardt et al., 2005; Palmer et al., 2007). Restoration projects provide an opportunity to apply basic ecological concepts, such as habitat heterogeneity (Palmer et al., 2010), and managed flow regimes (Poff and Ward, 1989) in an effort to max- imize the potential for restoration success (Palmer et al., 2005). They also pose a challenge to practitioners in that they require an explicit synthesis of hydrology and ecology, and many ecohydrological questions pertinent to restoration success remain unanswered (Palmer and Bernhardt, 2006). But stream restoration can contribute fundamentally to basic ecology as well: restoration projects often involve massive disturbances, channel creation, or other changes in environmental and biological conditions that are predictable and relatively controlled. As such, stream restoration sites can make ideal test sites for improving our understanding of many ecological principles, including disturbance, connectivity, and ecosystem functional response (Lake et al., 2007).

In this study, we characterize the spatio-temporal changes in aquatic macroinvertebrate communities along an experimental dewatering gradient. This research opportunity was made possible by a stream restoration at the site, which allowed conditions to be manipulated and ecological principles to be tested in a fairly rigorous fashion: the nature of the dewatering gradient and the predictable manipulation and timing of the dewatering allowed us to compare community responses to drought-like conditions at sites that became nearly dry simultaneously with nearby sites that were only minimally affected, and to do so at several intervals pre-, during-, and post-dewatering. Due to the unique geomorphology and history of the site, microhabitat refugia formation during the dewatering was minimal, so community responses would be due strictly to changes in metrics like channel depth or water quality.

\section{Methods}

\subsection{Site description}

This study was conducted at the Timberlake mitigation site, located near the Albemarle Sound estuary on the outer coastal plain of North Carolina (Fig. 1). Timberlake is a 1000 ha former corn/soybean field, and has been a site of riverine/wetland restoration and mitigation activity. It is low-lying and flat, with elevations ranging from -0.4 to $5.1 \mathrm{~m}$ a.s.l. and few naturally-occurring (non-agricultural) channels for water flow (Ardón et al., 2010). Restoration activities included digging new channels beginning in 2004 to enhance the lotic character of the site and turning off or closing the downstream pump/flapgate complex that had previously drained or dewatered the site to allow for agriculture. Turning off these pumps allowed 440 ha of the site to re-flood with freshwater to an average depth of $1 \mathrm{~m}$ in 2007; this area is the focus of this study. Under typical conditions, Timberlake is visually like a wetland; nonetheless, it maintains lotic character via downstream flowpaths and wind tides (Ardón et al., 2010; Fig. 1). Under dewatered conditions the flooded wetland mostly drained, emphasizing these lotic conditions because the only remaining water was located within the dug channel. 


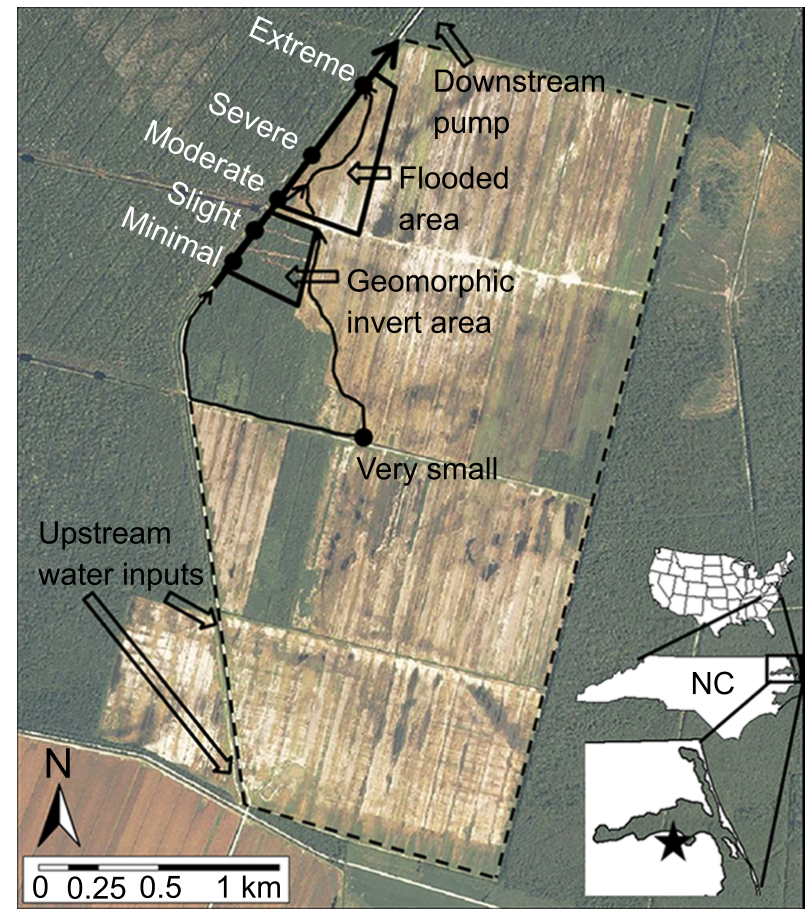

Fig. 1. Timberlake mitigation site (outlined in dashed line) in the Albermarle Sound region of North Carolina. The six sampling sites (circles) are named according to strength of the dewatering effect. Trapezoids designate approximate regions of the flooded area preand post-dewatering and the geomorphic invert that minimized the dewatering effect on more upstream sites. The solid, bold arrow outlines the path of the main gradient used in this study; smaller arrows indicate alternate water flow paths.

As part of ongoing research at Timberlake, an experimental drawdown of the water level was conducted on $18 \mathrm{Au}-$ gust 2008. This dewatering was initiated by opening the downstream flapgates, turning the downstream pumps back on, and allowing them to operate as they had during agricultural operations, which dewatered the site in $<1$ day. Rewetting occurred after 15 days of dewatered conditions by turning the pumps off again, re-flooding the site over $<1$ day on 2 September 2008. Hurricane Hanna also passed over the area on 5 September 2008 (3 days post-rewetting), exposing the site to additional water inputs from precipitation in addition to wind disturbance.

Not all wetted areas across the site were equally affected by this dewatering. When the primary channel was created during the restoration, a geomorphic invert was encountered where the grade of the land prevented a channel from being dug upstream past that region (Fig. 1). Whereas the main channels carrying water downstream below the geomorphic invert were fairly distinct, flowpaths above the invert were more diffuse and unchannelized (Bogardus, B., unpublished data). Following the initial re-flooding a beaver also created a dam in the geomorphic invert region, further segregating the hydrologic regime above and below the invert. As a result, the experimental dewatering exerted a gradient effect across the site, with the most downstream areas being most affected, while sites above the geomorphic invert were nearly undisturbed.

Our sampling design consisted of intensive repeat sampling at 6 sites along this dewatering gradient. Five sites were located along the major gradient. An additional 6th site was far upstream of the geomorphic invert, at a location that was not strongly hydrologically-connected to the other sites and that was meant to serve as an undisturbed control (Fig. 1). Each of these sites was sampled 7 times: 1 day predewatering at day 0 , during the dewatering at days 4,7 , and 14 , and post-dewatering and rewetting at days 20,26 , and 32 (the pumps were turned off on day 15).

\subsection{Channel cross sections and water quality}

The effect of the dewatering on riparian and channel habitat was quantified in part as change in wetted perimeter (WP) and depth using channel cross sections at all 6 sites. Wetted perimeter is defined as the length of the wetted cross section and is a common measure in fluvial geomorphology. Unlike a traditional geometric "perimeter" with 4 closed sides (in the case of a rectangle), wetted perimeter includes only 3 sides: the wetted portion of the banks and channel bed but not the water surface (thus, it is approximately $1 *$ width $+2 *$ depth for a near- rectangular channel; Gordon et al., 2004). Wetted perimeter was calculated using the Hydro ToolBox add-in for Microsoft Excel (Renshaw, 2008). Cross sections were surveyed using a total station (Trimble, Sunnyvale, CA, USA) at the first during-dewatering sample when the water level was at its lowest. Water level was also noted pre-dewatering by placing pin flags, which were then surveyed in with the rest of the cross section in addition to the dewatered water levels. The post-dewatering (rewetting) water level was similar to pre-dewatering, so no additional points were surveyed and water level at these 2 conditions is assumed to be equal for the analysis.

A suite of water quality parameters, including water temperature, specific conductivity ( $\mathrm{SpC}$, and correlated salinity), $\mathrm{pH}$, and oxidation-reduction potential (redox potential, ORP) were measured at the time of each sampling using a YSI 556 multiprobe (Yellow Springs, Ohio, USA). Most samples were taken in repeated locations under similar conditions at the same time of day; however, this was not always the case for every sample. As such, fluctuations in some measurements (especially temperature) did occur, as measurements between adjacent sample dates could be separated by as much as $2 \mathrm{~h}$ in terms of time of day of sampling. 


\subsection{Macroinvertebrate sampling}

Macroinvertebrates were collected at every site for every sampling event using a modification of the North Carolina Division of Water Quality "Swamp Method," which was designed for use in outer coastal plain ecosystems (like Timberlake) with little appreciable flow (NCDWQ, 2006). Our particular sampling strategy involved standing in a fixed location in the channel $1 \mathrm{~m}$ off the bank and sampling all habitats - including both the channel thalweg (deepest point) and bank macrophyte vegetation - within reach of a D-frame dip net (500-m mesh) with a $1.2 \mathrm{~m}$ handle. These samples were then field-picked exhaustively for $30 \mathrm{~min}$, which we estimate was sufficient to remove $>95 \%$ of macroinvertebrates from each sample. In rare cases where collected abundances were high enough to require more picking time, the sample remaining after $30 \mathrm{~min}$ was stored and picked to completion later under a magnifying glass in the laboratory. This type of sampling strategy is "semi-quantitative," but nonetheless allows reasonable estimates of macroinvertebrate abundance and density to be made and is standard practice for biomonitoring in NC state agencies (NCDWQ, 2006). All collected macroinvertebrates were stored in $95 \%$ ethanol and were identified using dichotomous keys (Holsinger, 1972; Williams, 1972; Merritt et al., 2008). To improve the strength of our community-level inferences, macroinvertebrates were identified to the highest resolution possible given our identification facilities. This was generally to the genus or species level, with the exception of some Diptera and non-Insecta that were identified to the family level or higher. Macroinvertebrates were also sorted into habitat classes (i.e. swimming, benthic, or hydrophyte-associated; see Supplement, Table S1). These classifications were based on life history characteristics for a given taxa (obtained from, e.g. Merritt et al., 2008) at the growth stage for which the macroinvertebrate was collected (generally late-instar larvae or adults).

Macroinvertebrate communities were analyzed primarily using a non-metric multi-dimensional scaling (NMS) ordination approach (Shepard, 1962; Kruskal, 1964) with a BrayCurtis distance measure (Bray and Curtis, 1957; McCune and Grace, 2002). All data were analyzed using R statistical software (R Development Core Team, 2009), especially within the contributed package vegan (Oksanen et al., 2009). After preliminary analysis, it became apparent that the community far above the geomorphic invert was quite different from the other 5 sites even before the dewatering (See Supplement, Fig. S1), likely due to the hydrologic disconnect between this site and the others (Fig. 1) and so it was removed from the macroinvertebrate portion of the analysis. To facilitate the interpretation of relationships between samples and to minimize apparently large dissimilarities based on rare taxa, only taxa present in 3 or more ( $\geq 5 \%$ ) of samples were kept in the dataset. Because samples and individual taxon abundances often varied by more than an order of magnitude, the data were $\log$-transformed $(\log (x+1))$ to minimize the effect of this spread (McCune and Grace, 2002). Although another transformation (e.g. square root) may not have required this monotonic (i.e. $x+1$ ) addition, we felt that the ecological rationale for the $\log$ distribution in nature (Limpert et al., 2001) made the log transformation the best choice. The appropriate number of axes for the ordination was determined using a step-down procedure from 6 axes, each with a maximum of 100 random starts to find a stable solution using the function metaMDS in vegan (McCune and Grace, 2002; Oksanen et al., 2009). Comparing a scree plot of stress values from these 6 ordinations suggested that the stable 3 -axis solution with a stress of 14.51 was best, and was used for the rest of the analysis.

Significance tests for differences between community groups (i.e. groupings at a site over time or at one time over all sites) were carried out using non-parametric permutational MANOVA tests (Anderson, 2001), again using BrayCurtis similarity (McCune and Grace, 2002) and the vegan package in R (Oksanen et al., 2009; R Development Core Team, 2009). Overall and pairwise differences in community variability (dispersion from the community centroid in ordination space) were assessed by permutational analysis of dispersion tests (Anderson, 2006) using either the PERMDISP or PERMDISP2 programs, depending on whether sample sizes for particular comparisons were equal (Anderson, 2004). Following convention in similar studies (e.g. Houseman et al., 2008) and most ecological studies in general (Cabin and Mitchell, 2000), p-values from the permutational MANOVAs were not corrected for multiple tests (i.e. no Bonferroni correction was done; Anderson, 2001). Such correction methods grossly inflate the risk of Type II error (Nakagawa, 2004), are difficult to interpret, and their correct application is ambiguous in studies such as this where multiple overarching null hypotheses are being tested (site and time in this case), each with several sub-tests (Moran, 2003; Perneger, 1998). Therefore, the $\mathrm{p}$-values shown here are uncorrected, such that we interpret a value below the $\alpha$ of 0.05 as significant.

\section{Results}

\subsection{Wetted perimeter, depth, and water quality}

Due to the geomorphic invert, dewatering-initiated changes in wetted perimeter were linearly-related to each site's proximity to the downstream pumps; although wetted perimeter at the most upstream site was nearly unaffected by dewatering, the change in wetted perimeter at the most downstream (extreme effect) site was dramatic (Table 1). The change in depth from pre/post- to during-dewatering followed the same pattern with an exception at the moderate effect site, where depth changed less than at any other site. The width:depth ratio of this site was higher than elsewhere, so while wetted perimeter changed consistently with the site's position 
Table 1. Wetted perimeter and depth (analogues for aquatic habitat availability) by site pre/post- and during-dewatering. Distance from pump is the stream distance from a given site to the downstream pump that controlled the dewatering.

\begin{tabular}{|c|c|c|c|c|c|c|c|c|c|}
\hline \multirow[b]{2}{*}{ Site } & \multirow{2}{*}{$\begin{array}{l}\text { Distance } \\
\text { from pump } \\
\quad(\mathrm{km})\end{array}$} & \multicolumn{4}{|c|}{ Wetted perimeter } & \multicolumn{4}{|c|}{ Depth } \\
\hline & & $\begin{array}{l}\text { Pre/Post } \\
\text { (m) }\end{array}$ & $\begin{array}{c}\text { During } \\
\text { (m) }\end{array}$ & $\begin{array}{c}\text { Change } \\
\text { (m) }\end{array}$ & $\begin{array}{c}\text { Change } \\
(\%)\end{array}$ & $\begin{array}{l}\text { Pre/Post } \\
\text { (m) }\end{array}$ & $\begin{array}{l}\text { During } \\
\text { (m) }\end{array}$ & $\begin{array}{c}\text { Change } \\
\text { (m) }\end{array}$ & $\begin{array}{c}\text { Change } \\
(\%)\end{array}$ \\
\hline Very small & 1.64 & 3.13 & 3.06 & -0.07 & $2.3 \%$ & 0.63 & 0.52 & -0.11 & $17.2 \%$ \\
\hline Minimal & 2.12 & 1.59 & 1.25 & -0.34 & $21.3 \%$ & 0.84 & 0.62 & -0.22 & $26.3 \%$ \\
\hline Slight & 2.40 & 2.50 & 1.68 & -0.81 & $32.6 \%$ & 0.83 & 0.61 & -0.22 & $26.8 \%$ \\
\hline Moderate & 2.52 & 2.99 & 1.67 & -1.32 & $44.1 \%$ & 1.16 & 1.02 & -0.14 & $11.7 \%$ \\
\hline Severe & 2.69 & 4.85 & 1.56 & -3.29 & $67.9 \%$ & 0.67 & 0.28 & -0.39 & $57.6 \%$ \\
\hline Extreme & 3.43 & 3.93 & 0.58 & -3.35 & $85.1 \%$ & 1.38 & 0.11 & -1.27 & $95.2 \%$ \\
\hline
\end{tabular}

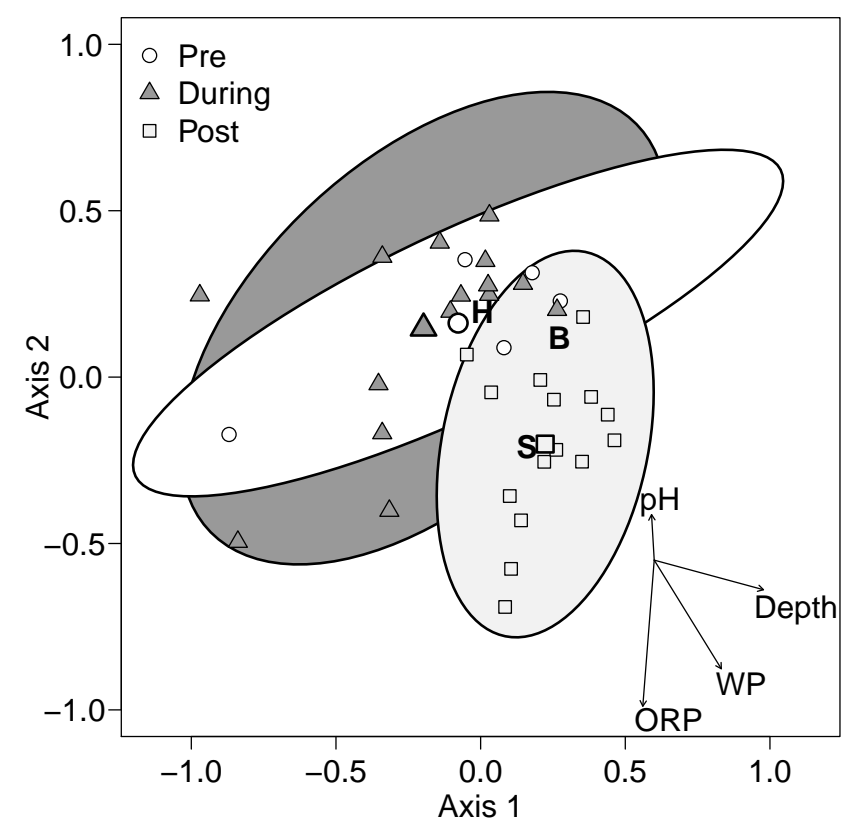

Fig. 2. Macroinvertebrate community NMS ordination joint biplot, with groupings by pre-, during-, and post-dewatering. Larger shapes represent group centroids. Letters represent taxa group locations on the biplot, " $\mathrm{H}$ " = hydrophyte-associated, "B"= benthic, and " $\mathrm{S}$ " = swimming. The joint plot on the bottom right indicates the direction and magnitude of the primary environmental gradients (WP = wetted perimeter). These 2 NMS axes capture 64.15 and $17.79 \%$ of the variation in the data, respectively. Ellipses are $95 \%$ confidence intervals.

along the dewatering gradient, most of this change was in the width, and depth was not as strongly affected.

Water temperatures varied somewhat over the course of the study, partially in response to variability in the time of day in which measurements were taken (Table 2). Additionally, temperature decreased over the course of the dewatering, increased for 12 days post-rewetting, then fell again. Measured values for $\mathrm{pH}$ varied from neutral to very acidic
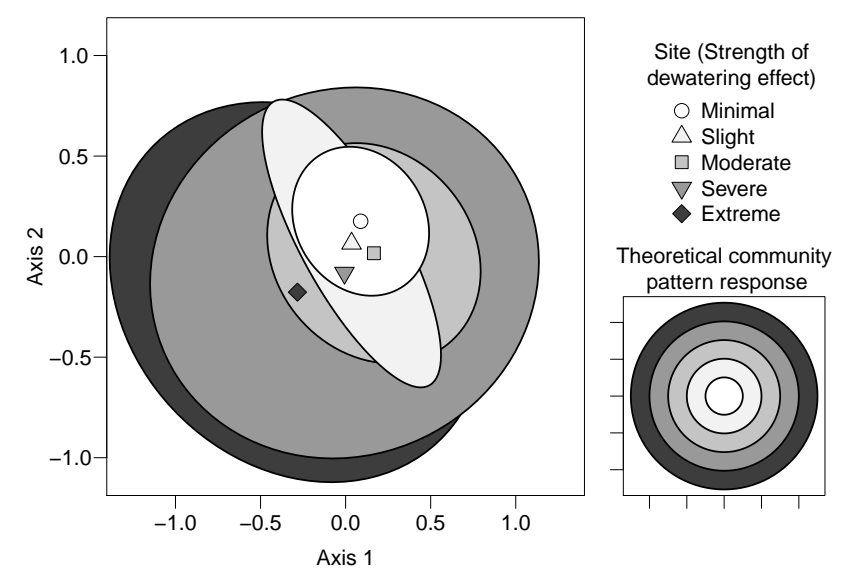

Fig. 3. The macroinvertebrate community NMS ordination, with groupings according to sample site (main panel). The smaller panel is a theoretical ordination of the communities showing increasing dispersion with dewatering severity extending outward in concentric circles. Ellipses are $95 \%$ confidence intervals.

and did not follow a consistent pattern over time, although the water at all sites was more acidic at the time of the last post-dewatering sample than pre-dewatering. Finally, specific conductivity results divided into 2 groups: the site with a very small dewatering effect had low, relatively stable $\mathrm{SpC}$ values throughout the study while $\mathrm{SpC}$ at the remaining 5 sites decreased throughout the dewatering, increased for 12 days post-rewetting, then dropped again by the last sample.

\subsection{Community responses}

Ordination analysis revealed distinguishable macroinvertebrate community groups. Axes 1 and 2 accounted for $81.94 \%$ of the variation in community data (Fig. 2). Fitting the environmental and habitat data to the ordination yielded 4 significant correlations to the axes (Table 3). Most notably, wetted perimeter and depth were correlated with the primary 
Table 2. Water quality measurements pre-, during-, and post-dewatering.

\begin{tabular}{|c|c|c|c|c|c|c|c|c|}
\hline Site & $\begin{array}{l}\text { Sample event } \\
\text { Time (\# days) } \\
\text { Sample time }\end{array}$ & $\begin{array}{c}\text { Pre } \\
\text { Day 0 } \\
\text { 16:00 }\end{array}$ & $\begin{array}{c}\text { During } 1 \\
\text { Day } 4 \\
11: 30\end{array}$ & $\begin{array}{c}\text { During } 2 \\
\text { Day } 7 \\
12: 00\end{array}$ & $\begin{array}{c}\text { During } 3 \\
\text { Day 14 } \\
11: 00\end{array}$ & $\begin{array}{c}\text { Post } 1 \\
\text { Day 20 } \\
11: 00\end{array}$ & $\begin{array}{c}\text { Post } 2 \\
\text { Day } 26 \\
10: 00\end{array}$ & $\begin{array}{c}\text { Post } 3 \\
\text { Day } 32 \\
\text { 12:00 }\end{array}$ \\
\hline \multirow{6}{*}{$\begin{array}{l}\text { Temperature } \\
\left({ }^{\circ} \mathrm{C}\right)\end{array}$} & Very small & 30.75 & 25.78 & 26.18 & 22.98 & 23.69 & 25.80 & 21.52 \\
\hline & Minimal & 24.96 & 23.35 & 23.31 & 22.47 & 24.63 & 25.63 & 21.53 \\
\hline & Slight & 31.11 & 23.97 & 25.02 & 22.22 & 25.72 & 27.03 & 20.78 \\
\hline & Moderate & 30.50 & 24.23 & 23.15 & 24.17 & 26.38 & 27.05 & 21.02 \\
\hline & Severe & 30.23 & 25.11 & 24.75 & 24.73 & 24.96 & 28.63 & 21.70 \\
\hline & Extreme & 30.37 & 32.28 & 32.50 & 29.15 & 25.80 & 26.37 & 22.69 \\
\hline \multirow{6}{*}{$\begin{array}{l}\text { Specific conductivity } \\
(\mathrm{SpC}),(\mathrm{mS} / \mathrm{cm})\end{array}$} & Very small & 0.51 & 0.53 & 0.52 & 0.57 & 0.54 & 1.36 & 1.75 \\
\hline & Minimal & 9.08 & 6.98 & 6.77 & 3.44 & 8.13 & 7.58 & 7.34 \\
\hline & Slight & 9.48 & 7.40 & 6.69 & 4.65 & 8.26 & 8.18 & 5.22 \\
\hline & Moderate & 10.30 & 6.20 & 5.57 & 4.06 & 8.30 & 8.96 & 5.29 \\
\hline & Severe & 9.86 & 6.05 & 5.57 & 3.87 & 8.40 & 8.61 & 5.67 \\
\hline & Extreme & 10.65 & 6.67 & 6.01 & 4.05 & 10.38 & 10.40 & 6.64 \\
\hline \multirow{6}{*}{$\mathrm{pH}$} & Very small & 5.22 & 4.79 & 4.71 & 4.50 & 4.43 & 3.99 & 3.85 \\
\hline & Minimal & 5.26 & 5.42 & 5.13 & 4.45 & 4.36 & 5.91 & 5.99 \\
\hline & Slight & 5.61 & 5.22 & 4.23 & 4.66 & 4.41 & 3.95 & 3.80 \\
\hline & Moderate & 5.29 & 5.07 & 4.55 & 5.12 & 4.47 & 5.63 & 3.69 \\
\hline & Severe & 6.89 & 4.16 & 4.17 & 3.93 & 4.62 & 4.34 & 3.80 \\
\hline & Extreme & 6.03 & 4.04 & 3.81 & 3.83 & 5.48 & 5.12 & 3.93 \\
\hline \multirow{6}{*}{$\begin{array}{l}\text { Redox potential } \\
(\mathrm{ORP}),(\mathrm{mV})\end{array}$} & Very small & 222 & 329 & 297 & 409 & 414 & 445 & 473 \\
\hline & Minimal & -6 & -174 & -65 & 125 & 430 & -48 & -163 \\
\hline & Slight & -170 & -93 & 225 & 17 & 396 & 426 & 368 \\
\hline & Moderate & 175 & -97 & 25 & -9 & 364 & 114 & 394 \\
\hline & Severe & 148 & 209 & 172 & 284 & 307 & 371 & 379 \\
\hline & Extreme & 54 & 377 & 429 & 383 & 266 & 233 & 419 \\
\hline
\end{tabular}

Table 3. Vector lengths of environmental and habitat variables to the ordination axes and variable correlation to the ordination. Statistically-significant correlations are in bold.

\begin{tabular}{lrrcc}
\hline & Axis 1 & Axis 2 & $r^{2}$ & $p$ \\
\hline Temperature & -0.892 & -0.451 & 0.120 & 0.080 \\
Specific conductivity (SpC) & 0.562 & -0.374 & 0.179 & 0.093 \\
pH & -0.025 & 0.365 & $\mathbf{0 . 2 5 0}$ & $\mathbf{0 . 0 2 8}$ \\
Redox potential (ORP) & -0.076 & -0.849 & $\mathbf{0 . 4 7 6}$ & $\mathbf{0 . 0 0 1}$ \\
Wetted perimeter (WP) & 0.547 & -0.770 & $\mathbf{0 . 3 1 9}$ & $\mathbf{0 . 0 0 5}$ \\
Depth & 0.952 & -0.224 & $\mathbf{0 . 2 8 0}$ & $\mathbf{0 . 0 1 2}$ \\
\hline
\end{tabular}

(first) axis, while ORP, wetted perimeter, and, to a lesser extent, $\mathrm{pH}$ and depth, were correlated with the secondary axis.

When samples from the 5 dewatering gradient sites were grouped together according to sampling event (pre-, during-, or post-dewatering; Fig. 2), results from permutational MANOVA tests suggested that each of these 3 communities differed from each other (Table 4). Because there was so little change in mean community composition (based on the group's centroid) from pre- to during-dewatering, the difference between these 2 communities may be inferred to be due to a change in community variability, or dispersion (Fig. 2). However, although a PERMDISP test showed an increase in dispersion from a value of 33.79 pre- to 35.65 during-dewatering, this difference was not significant (Table 5). In contrast, the difference between either the preor during-dewatering communities and the community that succeeded them post-rewetting was much more apparent as a change in the location of the community centroid, and the dispersions were again equal in pairwise comparisons (postrewetting dispersion $=32.39$; Table 5).

Distinguishable macroinvertebrate community patterns also emerged in ordination space when samples across time (sampling event) were grouped according to sample site (Fig. 3). Samples at the minimal dewatering effect site were the least variable through time, and variability increased incrementally along the dewatering gradient such that the community at the extreme dewatering effect site had greater dispersion over the course of the study (occupied 
Table 4. Results of permutational MANOVA tests for comparisons of macroinvertebrate communities grouped by event (pre-, during-, post-dewatering) and site (strength of dewatering impact). Statistically-significant community differences are in bold.

\begin{tabular}{llcc}
\hline \multicolumn{2}{l}{ Comparison } & $F$ & $p$ \\
\hline Event & Pre-during & $\mathbf{1 . 6 0 6}$ & $\mathbf{0 . 0 2 9}$ \\
& Pre-post & $\mathbf{1 . 5 5 4}$ & $\mathbf{0 . 0 0 1}$ \\
& During-post & $\mathbf{1 . 9 3 8}$ & $\mathbf{0 . 0 0 1}$ \\
& Overall & $\mathbf{3 . 2 6 3}$ & $\mathbf{0 . 0 0 1}$ \\
& & \\
Site & Minimal-slight & 1.307 & 0.087 \\
& Minimal-moderate & 1.384 & 0.058 \\
& Minimal-severe & 1.352 & 0.097 \\
& Minimal-extreme & $\mathbf{3 . 1 8 1}$ & $\mathbf{0 . 0 0 1}$ \\
& Slight-moderate & $\mathbf{1 . 4 5 0}$ & $\mathbf{0 . 0 2 3}$ \\
& Slight-severe & $\mathbf{1 . 5 8 1}$ & $\mathbf{0 . 0 3 1}$ \\
& Slight-extreme & $\mathbf{2 . 0 5 6}$ & $\mathbf{0 . 0 0 1}$ \\
& Moderate-severe & 1.019 & 0.195 \\
Moderate-extreme & $\mathbf{2 . 2 8 0}$ & $\mathbf{0 . 0 0 1}$ \\
& Severe-extreme & 1.818 & 0.065 \\
& Overall & $\mathbf{1 . 7 9 3}$ & $\mathbf{0 . 0 0 1}$ \\
\hline
\end{tabular}

more ordination space) than any other site grouping (statistically significant for 3 of 4 comparisons; Table 5). There was little difference in the centroids between any of these groups, and likely as a result only half of the pairwise combinations of these groups were significantly different based on permutational MANOVA. In the ordinations, communities at less dewatered sites existed within the ordination space of communities in more dewatered sites, forming a sort of "bull's-eye" pattern of roughly concentric circles (spheres in 3-D) in ordination space (Fig. 3). Consequently, 7 out of 10 pairwise comparisons of differences in dispersion between these groups were significant using PERMDISP, with the non-significant differences coming from comparisons between adjacent sites (Table 5).

Using succession vectors to track the macroinvertebrate community through time at each dewatering gradient site revealed consistent patterns in the ordination across the 5 sites (Fig. 4). In general, large community changes took place between the pre- and first during-dewatering samples (days 0 and 4 , respectively), but only at the sites where wetted perimeter and depth were most affected by the dewatering. Some community change continued to occur at all sites during the course of the dewatering, but then a large change occurred between the last dewatered and first post-rewetting samples at all sites; this was the largest (or equal to the largest) community change observed at 4 out of the 5 sites. Following this shift, the communities at those 4 sites all began a trajectory back to their initial (pre-dewatering) community structure that continued over the course of the rewetting, virtually achieving a return to pre-dewatering commu-
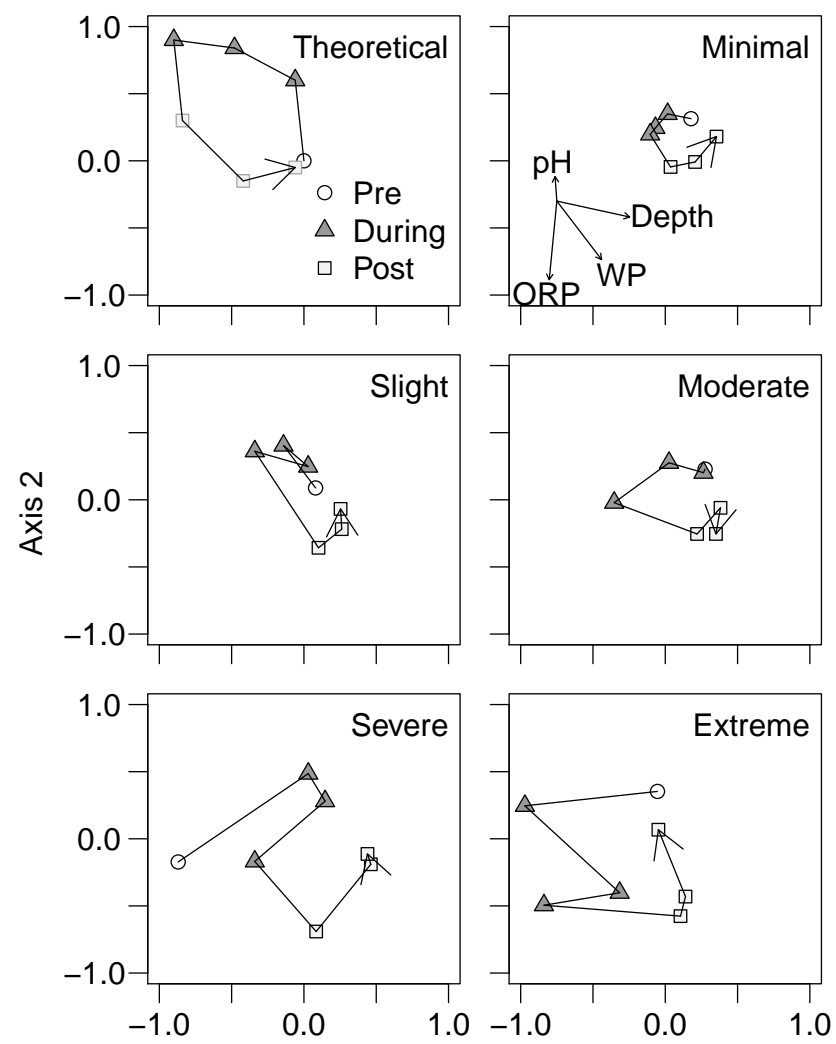

Axis 1

Fig. 4. Macroinvertebrate community NMS ordination, with each panel representing community trajectories through time at a given sample site.

nity similarity by the end of the study. The exception was the severely dewatered site, which seemed to change more stochastically through time.

The relative proportions of collected macroinvertebrates associated with distinct habitats (see Supplement, Table S1) also changed throughout the course of the study and especially at the extreme dewatering site, although the patterns were similar across all sites (Fig. 5). Prior to the dewatering, the community across all 5 gradient sites was dominated by hydrophyte-associated and benthic macroinvertebrate predators (e.g. Odonata and many Hemiptera taxa; Table 6). Pelagic or near-surface, swimming taxa (e.g. some Diptera and Hemiptera, but mostly the Coleopteran families Dytiscidae and Hydrophilidae) also contributed substantially to taxon richness pre-dewatering, but were low in abundance. Finally, benthic taxa pre-dewatering (e.g. Diptera, especially Chironomidae), in contrast, were fairly abundant at most sites, but contributed few taxa to richness counts.

Once the dewatering occurred, total and individual group macroinvertebrate abundance and richness stayed relatively constant, except for the hydrophyte-associated macroinvertebrates, which decreased in abundance by $56 \%$ across all 5 
Table 5. Results of PERMDISP tests for macroinvertebrate community dispersion comparisons grouped by event (pre-, during-, postdewatering) and site (strength of dewatering impact). The dispersion value for each group is listed adjacent to the group name. PERMDISP tvalues for the comparisons are shown, with corresponding p-values in parentheses. Statistically-significant community dispersion differences are in bold.

\begin{tabular}{lllll}
\hline Sampling event & Pre: 33.79 & During: 35.66 & & \\
$\begin{array}{l}\text { During: } 35.66 \\
\text { Post: } 32.39\end{array}$ & $0.379(0.754)$ & & & \\
& $0.271(0.826)$ & $1.010(0.381)$ & & \\
Site & Minimal: 40.45 & Slight: 45.76 & Moderate: 47.95 & Severe: 58.57 \\
Slight: 45.76 & $1.802(0.096)$ & & & \\
Moderate: 47.95 & $\mathbf{2 . 9 5 1 ( 0 . 0 1 7 )}$ & $0.802(0.448)$ & & \\
Severe: 58.57 & $\mathbf{3 . 5 2 6}(\mathbf{0 . 0 0 4})$ & $\mathbf{2 . 3 9 4}(\mathbf{0 . 0 1 2})$ & $\mathbf{2 . 0 8 1 ( \mathbf { 0 . 0 2 6 } )}$ & \\
Extreme: 63.97 & $\mathbf{6 . 8 2 4}(\mathbf{0 . 0 0 1})$ & $\mathbf{5 . 1 0 9}(\mathbf{0 . 0 0 1})$ & $\mathbf{5 . 1 0 8}(\mathbf{0 . 0 0 3})$ & $1.068(0.287)$ \\
\hline
\end{tabular}

Table 6. Macroinvertebrate abundance and richness at the 5 dewatered sites, grouped by habit pre-, during-, and post-dewatering.

\begin{tabular}{|c|c|c|c|c|c|c|c|c|c|}
\hline \multirow[b]{2}{*}{ Site } & \multirow[b]{2}{*}{ Sample event } & \multicolumn{4}{|c|}{ Abundance (average \# of individuals) } & \multicolumn{4}{|c|}{ Richness (average \# of taxa) } \\
\hline & & Swimming & Hydrophytes & Benthic & Total & Swimming & Hydrophytes & Benthic & Total \\
\hline \multirow[t]{3}{*}{ Minimal } & Pre & 7.0 & 70.0 & 74.0 & 151.0 & 3.0 & 5.0 & 2.0 & 10.0 \\
\hline & During & 26.7 & 40.7 & 23.3 & 90.7 & 5.7 & 5.0 & 1.7 & 12.3 \\
\hline & Post & 36.0 & 28.7 & 64.3 & 130.7 & 6.7 & 4.7 & 2.3 & 15.0 \\
\hline \multirow{3}{*}{ Slight } & Pre & 44.0 & 104.0 & 18.0 & 166.0 & 9.0 & 5.0 & 1.0 & 15.0 \\
\hline & During & 25.7 & 32.3 & 9.3 & 67.3 & 3.3 & 5.0 & 1.0 & 9.3 \\
\hline & Post & 110.7 & 21.0 & 28.3 & 162.0 & 9.0 & 4.7 & 1.3 & 16.7 \\
\hline \multirow[t]{3}{*}{ Moderate } & Pre & 11.0 & 55.0 & 85.0 & 151.0 & 7.0 & 7.0 & 1.0 & 15.0 \\
\hline & During & 13.7 & 22.3 & 75.0 & 111.7 & 6.3 & 5.0 & 2.7 & 14.7 \\
\hline & Post & 148.3 & 20.3 & 61.0 & 230.0 & 6.3 & 3.7 & 2.3 & 13.0 \\
\hline \multirow[t]{3}{*}{ Severe } & Pre & 2.0 & 27.0 & 2.0 & 31.0 & 2.0 & 4.0 & 1.0 & 7.0 \\
\hline & During & 21.0 & 29.7 & 49.0 & 99.7 & 5.3 & 5.0 & 2.3 & 12.7 \\
\hline & Post & 55.3 & 23.0 & 45.7 & 130.7 & 8.0 & 5.0 & 2.3 & 19.3 \\
\hline \multirow[t]{3}{*}{ Extreme } & Pre & 6.0 & 27.0 & 26.0 & 60.0 & 4.0 & 5.0 & 1.0 & 11.0 \\
\hline & During & 6.3 & 3.0 & 9.7 & 19.0 & 3.3 & 2.0 & 1.7 & 7.0 \\
\hline & Post & 25.3 & 7.7 & 13.0 & 46.7 & 6.7 & 2.7 & 1.3 & 11.3 \\
\hline
\end{tabular}

dewatered sites (Table 6). Abundance of this habitat group continued to decrease at most sites even post-rewetting, while swimmer abundance and richness increased. In fact, swimmer abundance post-rewetting increased by roughly an order of magnitude across all sites in comparison to predewatered levels, and became a more obvious component of the post-rewetting community (Fig. 2). Finally, overall macroinvertebrate abundance and richness across all groups at the 5 gradient sites also increased from during- to postdewatering.

\section{Discussion}

Macroinvertebrate community responses to the dewatering and subsequent rewetting differed, altering our initial conceptualization of the rewetting as a continuation of a persistent drought-type ramp disturbance (Lake, 2000). The pre-dewatering community incorporated aspects of both the during- and post-dewatering communities; however, these latter 2 communities emphasized different components of that initial community structure. For the initial dewatering- a pulse-type, large disturbance event that substantially disrupted habitat availability on a short time scale - 

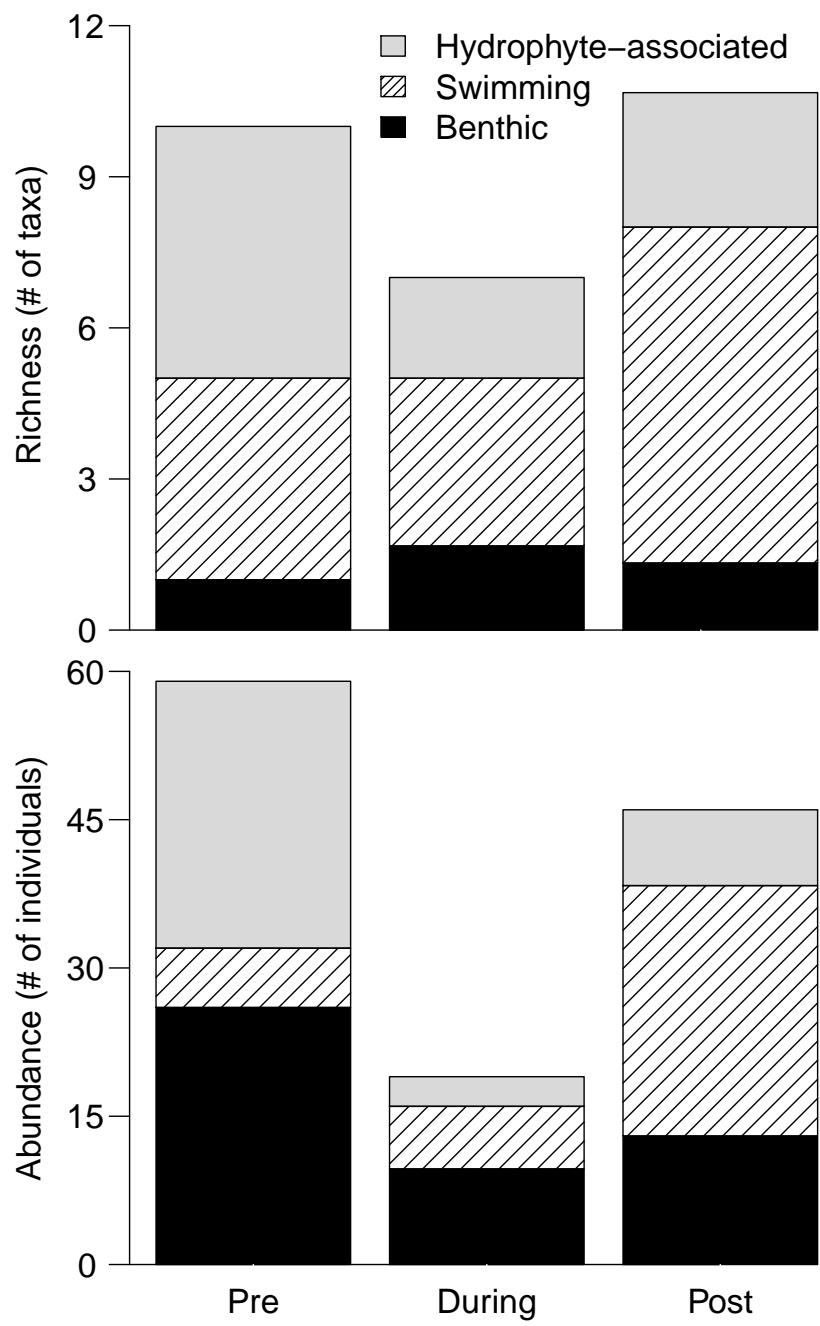

Fig. 5. Macroinvertebrate richness and abundance at the extreme dewatering site, grouped according to mobility/habit pre-, during-, and post-dewatering.

we had expected the macroinvertebrate community to be more dispersed during dewatered conditions relative to predewatering (Lake, 2000; Biggs et al., 2005). This pattern was observed in terms of raw dispersion values; however, the dispersion test indicated that this difference was not significant. More unexpectedly, the community did not become even more variable following rewetting. We had predicted the rewetting, due to its rapid nature, would serve as another disturbance and therefore might initiate a similar community change to that observed during the dewatering (Kelsch, 1994; Smock et al., 1994), but this did not occur. It is conceivable that this response might be because the community had been so retracted compositionally (i.e. to only the most resistant taxa; Miller and Golladay, 1996) during the dewatering that further changes post-rewetting would have been minor relative to the initial, dewatering-induced change. But, in fact, overall taxon abundance and richness actually returned to or even increased above pre-dewatering levels after the rewetting occurred. Succession vectors (Fig. 4) also indicated a return to original community composition at most sites. Thus, rewetting seems to have provided a rapid reset mechanism for the aquatic macroinvertebrate community at Timberlake.

Community change along the dewatering gradient was relative to the magnitude of habitat change exerted by the dewatering (primarily in the wetted perimeter), which is supported by research in other stream systems (Miller et al., 2007; James and Suren, 2009). Other environmental parameters ( $\mathrm{pH}$ and ORP) were related to the ordination as well. These parameters may have exerted some control on community structure along the second axis, which accounted for 17.79 of the variation in the data (Figs. 2, 4). Notably, ORP was strongly related to this second axis, more so than any other measured parameter (Table 3). In general, communities shifted in a positive direction along this second gradient (higher $\mathrm{pH}$, lower ORP) from pre-during dewatering, then shifted in a negative direction post- rewetting. Such shifts along the second axis were also strongly correlated to changes in wetted perimeter (and depth, to a lesser extent), and the trajectory of community change over time at the sites often closely tracked the gradient in this habitat parameter (Fig. 4).

One hypothesis regarding drought-type disturbances could be that communities respond according to threshold changes: below some threshold of habitat change the community remains relatively unperturbed, but then collapses or shifts to a new stable state (community mean) as the drought persists and removes some key habitat component (Chase, 2003; Suding et al., 2004). In streams, these thresholds may be directly related to water level, with stepped faunal changes when water levels drop below both banks, then below the bed surface, etc. (Boulton, 2003); however, this may not be the case when dewatering occurs rapidly. Such a threshold pattern also has not been supported by other stream dewatering studies (Suren et al., 2003; Dewson et al., 2007b; James and Suren, 2009) and does not seem to have been the case at Timberlake either. This assumes that there were no lag effects, whereby other species may have gradually disappeared if the dewatering had persisted more long-term (Boulton and Lake, 2008). However, we suspect that the magnitude of dewatering severity and the presence of "indirect effects" (Miller et al., 2007) resulting from very acidic $\mathrm{pH}$ values likely would have precluded any such lag response.

Rather than affecting the community mean, increasing severity of disturbance led to increasing community variability between samples at a site. When comparing all the sites, the magnitude of community change (as a function of variability) during the dewatering and rewetting could be viewed as a series of concentric rings in ordination space (Fig. 3). In this representation, sites that underwent the most dramatic changes in available habitat composed the large, outer rings, and communities at the less-affected sites made up the inner rings. This response is similar to the one shown 
by Houseman et al. (2008), where plant community dispersion in a grassland increased with greater magnitude of disturbance. Whereas all communities seemed to retain some degree of self-similarity to their initial condition (i.e. the community mean changed minimally; Warwick and Clarke, 1993), the sites most affected by dewatered conditions supported communities that emphasized more of the fringe of this community composition.

Wetted perimeter and depth seem to have exerted a strong control on the macroinvertebrate communities over the course of this study. Of course, wetted perimeter is interrelated to many other hydrological variables (Clausen and Biggs, 2000), but we chose to focus on this one, principal hydrologic driver as is common in such gradient effect research (Lancaster and Belyea, 2006). We note the apparent importance of other parameters (particularly ORP) to the secondary ordination axis as well; However, given the strong correlation of wetted perimeter to both axes, especially the predominant first axis, this parameter seems more likely to be the ultimate driver of community change throughout this study.

It is not surprising to find that a hydrologic variable controlled community composition over the course of this study given the wealth of previous research to support such a result (Poff et al., 1997). However, most other drought-type studies have particularly emphasized the importance of microscale refugia (e.g. small rock pools), rather than channel reach-scale hydrological variables like wetted perimeter, in maintaining vestiges of community structure during severe drought conditions (Dewson et al., 2007a). In fact, recovery from dewatering following rewetting is thought to be quite common in drought-type disturbances, but this is predicated mostly on the presence of hyporheic habitat and large woody debris that remain moist (Boulton, 2003; but see James and Suren, 2009). As a former agricultural field that has been restored to wetland/stream-like conditions but nonetheless lacks woody debris and maintains a homogeneous silt-sand bed (i.e. no heterogeneous water pooling and limited hyporheic habitat), refugia of this form were largely unavailable to the aquatic biota at Timberlake. Thus, hydrologic conditions, rather than a heterogeneous geomorphic mosaic (Pringle et al., 1988), had a large influence on the localized presence of aquatic biota. We suggest that wetted perimeter may be a good analogue for available habitat under such conditions.

The emphasis on the presence of water in providing habitat - rather than water and substrate - may explain the most noticeable changes in community composition in this study. At Timberlake, swimming and hydrophyteassociated taxa were primarily predaceous Coleoptera and Odonata/Hemiptera, respectively. When wetted perimeter shrank and bankside cattails and associated vegetation desiccated, hydrophyte-associated macroinvertebrates lost their optimal habitat and many apparently died, as indicated by declines in their abundance and richness that continued even post-rewetting (Fig. 5). This response is similar to that shown in English chalk streams, where maintaining submerged macrophytes is critical to minimizing the ecological effects of droughts (Wright and Berrie, 1987; Wright and Symes, 1999). In contrast to the hydrophyte-associated taxa, however, the most mobile, swimming taxa at Timberlake actually responded positively to the dewatering. Available habitat for these taxa (i.e. the pelagic zone) was decreased by the experimental dewatering, but this stress was not lethal to the entire population. Thus, when wetted conditions returned, swimmers were able to rapidly re-colonize (perhaps from the unaffected areas of Timberlake, such as those areas near or above the geomorphic invert) and to dominate post-rewetting. Such rapid re-colonization is possible when a nearby source population is present (Williams and Hynes, 1977; Malmqvist et al., 1991; Fowler, 2004), although in the case of severe droughts that persist for long periods of time (e.g. currently in Australia), this may be unlikely (Boulton, 2003; Boulton and Lake, 2008). Finally, because benthic macroinvertebrate (prey) abundances did not continue to decrease from during- to post-dewatering, hydrologic (dewatering/rewetting) control seems to have had an overriding influence on the abundance of these benthic prey as well.

\section{Conclusions}

Stream restoration sites, as locations of intentional manipulations to an ecosystem, can represent opportunities for research in basic ecological principles (Lake et al., 2007). In this study, the predictable nature of an experimental dewatering post-restoration allowed rigorous, structured sampling to occur pre-, during-, and post-dewatering, which is difficult in systems not controlled by an electric pump and flap gates. This dewatering itself was clearly experimental and occurred over a fairly short timescale. However, late summer is a feasible time for low-flow conditions to occur in the Southeastern US and the rapid rewetting of the site is not unlike hurricane-type precipitation that also can occur regionally in late summer-early fall, so this experimental manipulation was not without natural climatic precedent (Smock et al., 1994). Hurricane Hanna, which passed over the site 3 days post-rewetting, was a serendipitous reminder of this fact. In addition, the main drivers of community change induced by the dewatering- decrease in wetted perimeter and loss of bankside hydrophytes- are path-independent endpoints of any severe dewatering (including droughts, agricultural withdrawals, etc.), regardless of whether the disturbance itself is pulsed or ramps up in intensity. Thus, we believe it may be possible to extrapolate the conclusions of this study to natural droughts occurring at least on seasonal timescales.

We particularly note that hydrologic conditions (e.g. wetted perimeter) should not be de-emphasized in favor of discussing species migration to micro-scale areas of geomorphic refugia. In fact, wetted perimeter in the absence of 
geomorphic heterogeneity was a fairly good analog for available habitat in this study. Thus, we suggest a dualistic approach in future dewatering studies that incorporates both the hydrologic and geomorphic aspects of habitat alteration may be most beneficial. Also, rewetting (even rapid rewetting) at Timberlake seemed to represent an end to the dewatering disturbance, rather than a continuation of it. Nonetheless, community recovery to a fully pre-disturbed condition may take longer than initial response to dewatering, as the balance between displaced taxa and open-niche opportunists is slowly restored. Finally, we note that dewaterings may not always represent a threshold-type disturbance for biota; rather, biotic response in our study varied incrementally with dewatering severity. This was predominantly in the form of increases in community variability (dispersion), rather than a shift in the community mean. Thus, we suggest that explicit characterization of dispersion may be important in understanding the impacts of disturbance on ecological communities.

\section{Supplementary material related to this article is available online at: http://www.hydrol-earth-syst-sci.net/15/1771/2011/ hess-15-1771-2011-supplement.pdf.}

Acknowledgements. We thank the Doyle and Bernhardt labs, J. M. Muehlbauer, and especially B. Bogardus for their assistance. D. Urban also provided helpful advice on the statistics. We appreciate the helpful suggestions of anonymous reviewers in improving this manuscript.This work was supported by a NABS Endowment Award to JDM, the UNC Institute for the Environment, and NSF grant BCS-0441504 to MWD.

Edited by: E. Mitchell

\section{References}

Anderson, M.: A new method for non-parametric multivariate analysis of variance, Austral. Ecol., 26, 32-46, doi:10.1111/j.14429993.2001.tb00081.x, 2001.

Anderson, M.: Distance-based tests for homogeneity of multivariate dispersions, Biometrics, 62, 245-253, doi:10.1111/j.15410420.2005.00440.x, 2006.

Anderson, M. J.: PERMDISP: a FORTRAN computer program for permutational analysis of multivariate dispersions (for any twofactor ANOVA design) using permutation tests, available at: http: //www.stat.auckland.ac.nz/ mja/Programs.htm\#Mine, last access: 12 April 2010, Department of Statistics, University of Auckland, Auckland, 2004.

Ardón, M., Morse, J. L., Doyle, M. W., and Bernhardt, E. S.: The water quality consequences of restoring wetland hydrology to a large agricultural watershed in the southeastern coastal plain, Ecosystems, 13, 1060-1078, doi:10.1007/s10021-010-9374-x, 2010.

Bernhardt, E. S., Palmer, M. A., Allan, J. D., Alexander, G., Barnas, K., Brooks, S., Carr, J., Clayton, S., Dahm, C., FollstadShah, J., Galat, D., Gloss, S., Goodwin, P., Hart, D., Hassett, B.,
Jenkinson, R., Katz, S., Kondolf, G. M., Lake, P. S., Lave, R., Meyer, J. L., O’Donnell, T. K., Pagano, L., Powell, B., and Sudduth, E.: Synthesizing US river restoration efforts, Science, 308, 636-637, doi:10.1126/science.1109769, 2005.

Biggs, B. J. F., Nikora, V. I., and Snelder, T. H.: Linking scales of flow variability to lotic ecosystem structure and function, River Res. Appl., 21, 283-298, doi:10.1002/rra.847, 2005.

Bond, N. R., Lake, P. S., and Arthington, A. H.: The impacts of drought on freshwater ecosystems: an Australian perspective, Hydrobiologia, 600, 3-16, doi:10.1007/s10750-008-9326z, 2008.

Boulton, A. J.: Parallels and contrasts in the effects of drought on stream macroinvertebrate assemblages, Freshwater Biol., 48, 1173-1185, doi:10.1046/j.1365-2427.2003.01084.x, 2003.

Boulton, A. J. and Lake, P. S.: Effects of drought on stream insects and its ecological consequences, in: Aquatic Insects: Challenges to Populations: Proceedings of the Royal Entomological Society's 24th Symposium, edited by: Lancaster, J. and Briers, R. A., CAB International, Oxfordshire, 81-102, 2008.

Bray, J. R. and Curtis, J. T.: An ordination of the upland forest communities of Southern Wisconsin, Ecol. Monogr., 27, 325349, 1957.

Bunn, S. E. and Arthington, A. H.: Basic principles and ecological consequences of altered flow regimes for aquatic biodiversity, Environ. Manage., 30, 492-507, doi:10.1007/s00267-002-27370, 2002.

Cabin, R. J. and Mitchell, R. J.: To Bonferroni or not to Bonferroni: when and how are the questions, B. Ecol. Soc. Am., 81, 246-248, doi:10.1890/0012-9623(2000)081[0223:C]2.0.CO;2, 2000.

Chase, J. M.: Community assembly: when should history matter?, Oecologia, 136, 489-498, doi:10.1007/s00442-003-1311-7, 2003.

Clausen, B. and Biggs, B. J. F.: Flow variables for ecological studies in temperate streams: groupings based on covariance, J. Hydrol., 237, 184-197, doi:10.1016/s0022-1694(00)00306-1, 2000.

Clements, F. E.: Nature and structure of the climax, J. Ecol., 24, 252-284, 1936.

Collins, S. L.: Disturbance frequency and community stability in native tallgrass prairie, Am. Nat., 155, 311-325, 2000.

Connell, J. H.: Diversity in tropical rain forests and coral reefs, Science, 199, 1302-1310, 1978.

Dewson, Z. S., James, A. B. W., and Death, R. G.: A review of the consequences of decreased flow for instream habitat and macroinvertebrates, J. N. Am. Benthol. Soc., 26, 401-415, doi:10.1899/06-110.1, 2007a.

Dewson, Z. S., James, A. B. W., and Death, R. G.: Invertebrate responses to short-term water abstraction in small New Zealand streams, Freshwater Biol., 52, 357-369, doi:10.1111/j.13652427.2006.01682.x, 2007b.

Fowler, R. T.: The recovery of benthic invertebrate communities following dewatering in two braided rivers, Hydrobiologia, 523 , 17-28, doi:10.1023/B:HYDR.0000033077.13139.7f, 2004.

Gislason, J. C.: Aquatic insect abundance in a regulated stream under fluctuating and stable diel flow patterns, N. Am. J. Fish. Manage., 5, 39-46, doi:10.1577/15488659(1985)5<39:AIAIAR > 2.0.CO;2, 1985.

Gordon, N. D., McMahon, T. A., Finlayson, B. L., Gippel, C.J., and Nathan, R. J.: Stream Ecology: An Introduction for Ecologists, 2nd edition, Jon Wiley and Sons, Chichester, 2004. 
Hart, D. D. and Finelli, C. M.: Physical-biological coupling in streams: the pervasive effects of flow on benthic organisms, Annu. Rev. Ecol. Syst., 30, 363-395, doi:10.1146/annurev.ecolsys.30.1.363, 1999.

Holsinger, J. R.: The Freshwater Amphipod Crustaceans (Gammaridae) of North America, Biota of Freshwater Ecosystems Identification Manual, volume 5, US Environmental Protection Agency, Washington, DC, 1972.

Houseman, G. R., Mittelbach, G. G., Reynolds, H. L., and Gross, K. L.: Perturbations alter community convergence, divergence, and formation of multiple community states, Ecology, 89, 2172-2180, doi:10.1890/07-1228.1, 2008.

James, A. B. W. and Suren, A. M.: The response of invertebrates to a gradient of flow reduction - an instream channel study in a New Zealand lowland river, Freshwater Biol., 54, 2225-2242, doi:10.1111/j.1365-2427.2009.02254.x, 2009.

James, A. B. W., Dewson, Z. S., and Death, R. G.: Do stream macroinvertebrates use instream refugia in response to severe short-term flow reduction in New Zealand streams?, Freshwater Biol., 53, 1316-1334, doi:10.1111/j.1365-2427.2008.01969.x, 2008.

Kelsch, S. W.: Lotic fish-community structure following transition from severe drought to high discharge, J. Freshwater Ecol., 9, 331-342, 1994.

Konrad, C. P., Brasher, A. M. D., and May, J. T.: Assessing streamflow characteristics as limiting factors on benthic invertebrate assemblages in streams across the Western United States, Freshwater Biol., 53, 1983-1998, doi:10.1111/j.13652427.2008.02024.x, 2008.

Kruskal, J. B.: Multidimensional scaling by optimizing goodness of fit to a nonmetric hypothesis, Psychometrika, 29, 1-27, 1964.

Lake, P. S.: Disturbance, patchiness, and diversity in streams, J. N. Am. Benthol. Soc., 19, 573-592, 2000.

Lake, P. S.: Ecological effects of perturbation by drought in flowing waters, Freshwater Biol., 48, 1161-1172, doi:10.1046/j.13652427.2003.01086.x, 2003.

Lake, P. S., Bond, N., and Reich, P.: Linking ecological theory with stream restoration, Freshwater Biol., 52, 597-615, doi:10.1111/j.1365-2427.2006.01709.x, 2007.

Lancaster, J. and Belyea, L. R.: Defining the limits to local density: alternative views of abundance-environment relationships, Freshwater Biol., 51, 783-796, doi:10.1111/j.13652427.2006.01518.x, 2006.

Lepori, F. and Malmqvist, B.: Deterministic control on community assembly peaks at intermediate levels of disturbance, Oikos, 118, 471-479, doi:10.1111/j.1600-0706.2008.16989.x, 2009.

Limpert, E., Stahel, W. A., and Abbt, M.: Log-normal distributions across the sciences: keys and clues, Bioscience, 51, 341-352, doi:10.1641/0006-3568(2001)051[0341:LNDATS]2.0.CO;2, 2001.

Malmqvist, B., Rundle, S., Brönmark, C., and Erlandsson, A.: Invertebrate colonization of a new, man-made stream in Southern Sweden, Freshwater Biol., 26, 307-324, doi:10.1111/j.13652427.1991.tb01737.x, 1991.

McCune, B. and Grace, J. B.: Analysis of Ecological Communities, MjM Software Design, Gleneden Beach, 2002.

Merritt, R., Cummins, K., and Berg, M.: An Introduction to the Aquatic Insects of North America, 4th edition, Kendall Hunt, Dubuque, 2008.
Miller, A. M. and Golladay, S. W.: Effects of spates and drying on macroinvertebrate assemblages of an intermittent and a perennial prairie stream, J. N. Am. Benthol. Soc., 15, 670-689, 1996.

Miller, S. W., Wooster, D., and Li, J.: Resistance and resilience of macroinvertebrates to irrigation water withdrawals, Freshwater Biol., 52, 2494-2510, doi:10.1111/j.1365-2427.2007.01850.x, 2007.

Moran, M. D.: Arguments for rejecting the sequential Bonferroni in ecological studies, Oikos, 100, 403-405, doi:10.1034/j.16000706.2003.12010.x, 2003.

Nakagawa, S.: A farewell to Bonferroni: the problems of low statistical power and publication bias, Behav. Ecol., 15, 1044-1045, doi:10.1093/beheco/arh107, 2004.

North Carolina Division of Water Quality Biological Assessment Unit: Standard operating procedures for benthic macroinvertebrates, Report, Raleigh, 2006.

Oksanen, J., Kindt, R., Legendre, P., O’Hara, B., Simpson, G. L., Solymos, P., Stevens, M. H. H., and Wagner, H.: Vegan: Community Ecology Package, version 1.15, available at: http:// CRAN.R-project.org/package=vegan, last access: 28 May 2009, R Foundation for Statistical Computing, Vienna, 2009.

Palmer, M., Allan, J. D., Meyer, J., and Bernhardt, E. S.: River restoration in the twenty-first century: data and experiential knowledge to inform future efforts, Restor. Ecol., 15, 472-481, doi:10.1111/j.1526-100X.2007.00243.x, 2007.

Palmer, M. A. and Bernhardt, E. S.: Hydroecology and river restoration: ripe for research and synthesis, Water Resour. Res., 42, W03S07, doi:10.1029/2005wr004354, 2006.

Palmer, M. A., Bernhardt, E. S., Allan, J. D., Lake, P. S., Alexander, G., Brooks, S., Carr, J., Clayton, S., Dahm, C. N., Follstad Shah, J., Galat, D. L., Loss, S. G., Goodwin, P., Hart, D. D., Hassett, B., Jenkinson, R., Kondolf, G. M., Lave, R., Meyer, J. L., O'Donnell, T. K., Pagano, L., and Sudduth, E.: Standards for ecologically successful river restoration, J. Appl. Ecol., 42, 208217, doi:10.1111/j.1365-2664.2005.01004.x, 2005.

Palmer, M. A., Menninger, H. L., and Bernhardt, E.: River restoration, habitat heterogeneity and biodiversity: a failure of theory or practice?, Freshwater Biol., 55, 205-222, doi:10.1111/j.13652427.2009.02372.x, 2010.

Perneger, T. V.: What's wrong with Bonferroni adjustments, Brit. Med. J., 316, 1236-1238, 1998.

Poff, N. L. and Ward, J. V.: Implications of streamflow variability and predictability for lotic community structure: a regional analysis of streamflow patterns, Can. J. Fish. Aquat. Sci., 46, 18051818, 1989.

Poff, N. L., Allan, J. D., Bain, M. B., Karr, J. R., Prestegaard, K. L., Richter, B. D., Sparks, R. E., and Stromberg, J. C.: The natural flow regime, Bioscience, 47, 769-784, 1997.

Pringle, C. M., Naiman, R. J., Bretschko, G., Karr, J. R., Oswood, M. W., Webster, J. R., Welcomme, R. L., and Winterbourn, M. J.: Patch dynamics in lotic systems: the stream as a mosaic, J. N. Am. Benthol. Soc., 7, 503-524, 1988.

R Development Core Team: R: a language and environment for statistical computing, http://www.R-project.org, last access: 28 May 2009, R Foundation for Statistical Computing, Vienna, 2009.

Rader, R. B. and Belish, T. A.: Influence of mild to severe flow alterations on invertebrates in three mountain streams, Regul. River., 15, 353-363, doi:10.1002/(SICI)1099- 
1646(199907/08)15:4<353::AID-RRR551_3.0.CO;2-U, 1999.

Renshaw, C. E.: Hydro ToolBox Excel Add-in, version 1.3 Beta, available at: http://www.dartmouth.edu/ renshaw/hydrotoolbox, last access: 24 June 2009, Dartmouth College Department of Earth Sciences, Hanover, 2008.

Resh, V. H., Brown, A. V., Covich, A. P., Gurtz, M. E., Li, H. W., Minshall, G. W., Reice, S. R., Sheldon, A. L., Wallace, J. B., and Wissmar, R. C.: The role of disturbance in stream ecology, J. N. Am. Benthol. Soc., 7, 433-455, 1988.

Robinson, C. T. and Uehlinger, U.: Experimental floods cause ecosystem regime shift in a regulated river, Ecol. Appl., 18, 511526, doi:10.1890/07-0886.1, 2008.

Shepard, R. N.: The analysis of proximities: multidimensional scaling with an unknown distance function, II, Psychometrika, 27, 219-246, 1962.

Smock, L. A., Smith, L. C., Jones, J. B., and Hooper, S. M.: Effects of drought and a hurricane on a coastal headwater stream, Arch. Hydrobiol., 131, 25-38, 1994.

Suding, K. N., Gross, K. L., and Houseman, G. R.: Alternative states and positive feedbacks in restoration ecology, Trends Ecol. Evol., 19, 46-53, doi:10.1016/j.tree.2003.10.005, 2004.

Suren, A. M. and Jowett, I. G.: Effects of floods versus low flows on invertebrates in a New Zealand gravel-bed river, Freshwater Biol., 51, 2207-2227, doi:10.1111/j.1365-2427.2006.01646.x, 2006.
Suren, A. M., Biggs, B. J. F., Duncan, M. J., Bergey, L., and Lambert, P.: Benthic community dynamics during summer low-flows in two rivers of contrasting enrichment 2. Invertebrates, New Zeal. J. Mar. Fresh., 37, 71-83, doi:10.1080/00288330.2003.9517147, 2003.

Warwick, R. M. and Clarke, K. R.: Increased variability as a symptom of stress in marine communities, J. Exp. Mar. Biol. Ecol., 172, 215-226, 1993.

Williams, D. D. and Hynes, H. B. N.: Benthic community development in a new stream, Can. J. Zoolog., 55, 1071-1076, 1977.

Williams, W. D.: Freshwater Isopods (Asellidae) of North America, Biota of Freshwater Ecosystems Identification Manual, volume 7, US Environmental Protection Agency, Washington, D.C., 1972.

Wright, J. F. and Berrie, A. D.: Ecological effects of groundwater pumping and a natural drought on the upper reaches of a chalk stream, Regul. River., 1, 145-160, doi:10.1002/rrr.3450010205, 1987.

Wright, J. F. and Symes, K. L.: A nine-year study of the macroinvertebrate fauna of a chalk stream, Hydrol. Process., 13, 371-385, 10.1002/(SICI)1099-1085(19990228)13:3<371::AIDHYP744¿3.0.CO;2-C, 1999. 